\title{
Can transrectal prostate ultrasound compete with multiparametric MRI in the detection of clinically significant prostate cancer?
}

\author{
Alistair D. R. Grey ${ }^{1,2,3,4}$, Martin J. Connor ${ }^{1}$, Joseph Tam ${ }^{1}$, Tillmann Loch $^{5}$ \\ ${ }^{1}$ Imperial Prostate, Department of Surgery and Cancer, Faculty of Medicine, Imperial College London, London, UK; ${ }^{2}$ Division of Surgical and \\ Interventional Sciences, Faculty of Medicine, University College London, London, UK; ${ }^{3}$ Department of Urology, Barts and The Royal London \\ Hospitals, London, UK; ${ }^{4}$ Department of Urology, University College London Hospitals NHS Foundation Trust, London, UK; ${ }^{5}$ Department of \\ Urology Diakonissenkrankenhaus, Flensburg, University Teaching Hospital of Christian-Albrechts-Universität Kiel, Flensburg, Germany \\ Contributions: (I) Conception and design: All authors; (II) Administrative support: None; (III) Provision of study materials or patients: ADR Grey, T \\ Loch; (IV) Collection and assembly of data: ADR Grey, T Loch; (V) Data analysis and interpretation: ADR Grey, T Loch; (VI) Manuscript writing: \\ All authors; (VII) Final approval of manuscript: All authors. \\ Correspondence to: Alistair D. R. Grey. $3^{\text {rd }}$ Floor, Charles Bell House, 43-45 Foley St, London, W1W 7TS, UK. Email: alistair.grey@ucl.ac.uk.
}

\begin{abstract}
We consider the current and future role of transrectal ultrasound imaging in the diagnosis of prostate cancer, with a particular focus on the pre-biopsy localization and targeting role that multiparametric MRI (mpMRI) has come to occupy for some men in recent years. We draw a distinction between transrectal ultrasound (TRUS) used only as a means of distributing zonal biopsies with its employment as a means for identifying and targeting sonographically abnormal lesions. The role of AI in lesion identification and targeting will be reviewed. Comparisons of cost and availability, frequency of contraindications and diagnostic accuracy between these two imaging modalities will be drawn.
\end{abstract}

Keywords: Prostate cancer; multiparametric ultrasound; multiparametric MRI (mpMRI); artificial neural network analysis; transrectal ultrasound (TRUS)

Submitted Aug 31, 2019. Accepted for publication Feb 21, 2020.

doi: $10.21037 /$ tau.2020.02.26

View this article at: http://dx.doi.org/10.21037/tau.2020.02.26

\section{Introduction}

Technological advance has fostered huge shifts in the methods available for detecting prostate cancer in recent years. The diagnostic frailties of the accepted standard, transrectal (TR) biopsy, consisting usually of twelve cores systematically placed without any information about the likely position of disease, have been well demonstrated in high quality clinical trials $(1,2)$. PROMIS showed that 12 core TR bx could miss $52 \%$ of clinically significant prostate cancer in a cohort of patients undergoing prior transperineal biopsy as a reference standard, though didn't address targeting. PRECISION revealed the superiority, in comparative rates of cancer detection, of a small number of MRI targeted biopsy cores over four times that number systematically deployed in a zonal distribution. Multicentre randomized trial evidence comparing histology from targeted biopsy of lesions identified on ultrasound versus the equivalent from MRI apparent abnormalities is awaited.

Concerns over the relatively high complication rates of transrectal biopsy, in particular its potential to trigger septicaemia, are well documented (3) and become ever more relevant at a time of when increasing bacterial resistance prompts the use of second or third line agents (4) and the emergence of novel drugs is rare (5).

Despite these problems, adoption of the newer techniques amongst the urological community has been far from universal. Transperineal mapping biopsy in the absence of image guidance involves significant resource use and morbidity (6), hindering its application as a first tier technique. MRI/USS fusion systems offer the opportunity to reduce core numbers over pure mapping strategies but themselves add cost and procedure time. 


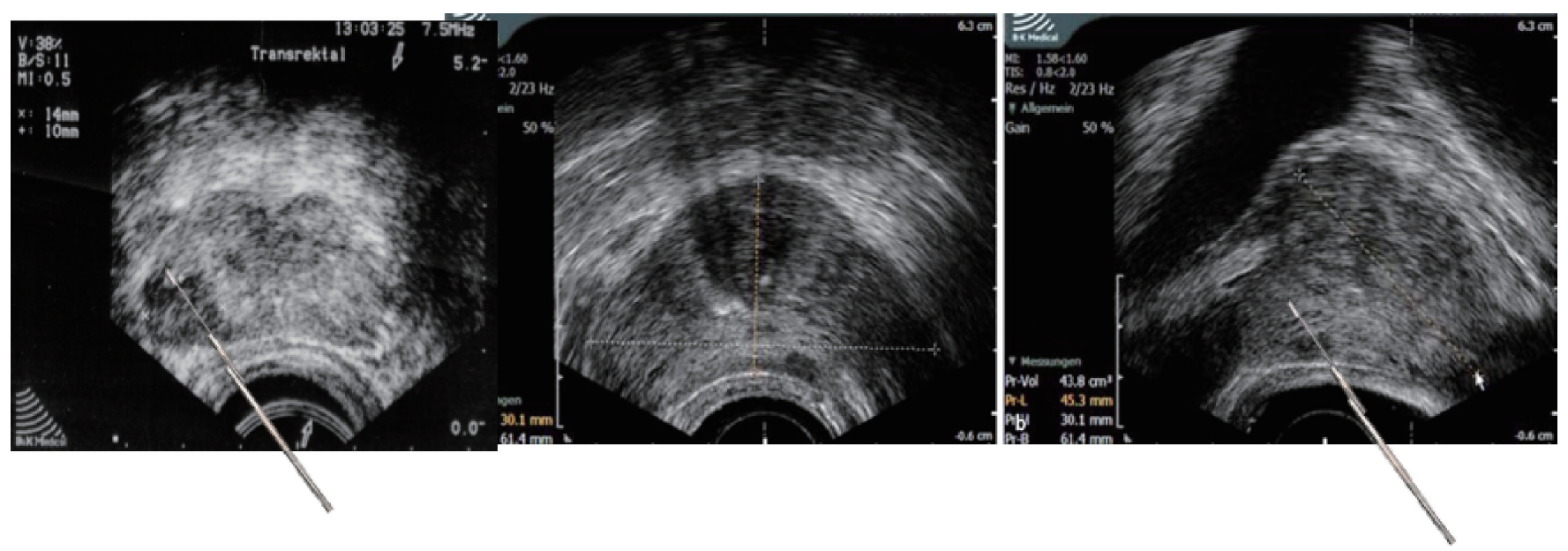

Figure 1 Targeting of sonographically abnormal lesions on b-mode ultrasound. Left and middle: 1 and $0.5 \mathrm{~cm}$ hypoechoic lesion on transverse image. Left transverse and right longitudinal image: simulation of optimal TRUS lesion targeted biopsy.

MRI targeted biopsy has been shown to perform well when compared with unguided transperineal prostate mapping $(7,8)$ but it's role in major international guidelines $(9,10)$ remains varied. Issues around cost and availability, both of equipment and expertise, mean that men presenting for the first time with a suspicion of prostate cancer may be offered tests that are both less accurate and carry more risk than they will encounter if cancer stays a suspicion after a negative round of testing. Whilst the lag in rollout of an MRI targeted approach due to training is a problem that might be overcome in a relatively few years, the impediment in cost and availability of MRI itself is likely to prove more intransigent. Ethnic variation (11) in prostate cancer risk means that need is greatest in developing parts of the world such as sub-Saharan Africa where availability is least.

Ultrasound scanners predate MRI by some 35 years $(12,13)$ and their use in the guidance of prostate biopsies has been established over several decades (14). Newer technologies offer the chance for a detection process similar to mpMRI, where prostate images using multiple ultrasound modalities may be cross referenced with the potential to improve upon the diagnostic performance of single (Figure 1) or dual modality ultrasound scans (15). Algorithmic interpretation shows promise also (16) in extracting information from imaging studies that visual analysis may not.

Success in any competition is a function of the rules of play. In the following paragraphs we consider the characteristics both of performance and utility that distinguish prostate ultrasound from MRI and consider the evidence relevant to the current and future potential of ultrasound scanners to localise prostate cancer.

\section{Cost and availability}

There is, at least for the moment inherent expense in a scanning technology dependent on supercooled electromagnets and the changes in quantum characteristics that they produce . Though pre-biopsy mpMRI is more frequently employed today than when its utility was first mooted (17) it's far from ubiquitous. Willingness to fund MRI before a first biopsy is variable across developed world healthcare systems and in the developing world the situation is far worse. Ogbole and colleagues (18) examined MRI availability in sub-Saharan Africa and found 87 machines available to a population of 373 million, a number profoundly unsuited to the provision of prebiopsy prostate MRI. Furthermore, the majority (77\%) of these were of low field strengths, $\leq 0.3$ Tesla, incapable of carrying out the multiparametric scans required for prostate cancer localization.

Ultrasound scanners suitable for prostate imaging cost in the region of $£ 100,000$ and software upgrades to allow for imaging modalities such as elastography, contrast enhanced ultrasound artificial neural network enhanced, discussed below, a few thousand each. Whilst by no means cheap this is in the order of ten times less than the equivalent MRI. Ultrasound machines are innately portable, adding further to their potential availability to populations where MRI is unfeasible. Scanning times are similar though perhaps favour ultrasound; in one author's institution a dedicated prostate 
Table 1 Comparison basic of US and MR characteristics

\begin{tabular}{lll}
\hline Attribute & Ultrasound & MRI \\
\hline Anatomic resolution & $1 \mathrm{~mm}$ for $8 \mathrm{MHz}$ & $1 \mathrm{~mm}$ \\
& Less at higher transducer frequency & \\
$\begin{array}{l}\text { Contrast } \\
\text { enhancement }\end{array}$ & True dynamic contrast-every moment of wash in captured & Image capture limitations means series of discrete \\
& Initial wash in viewable only for chosen 2 dimensional plane & True 3 dimensional capture \\
Tissue structure & Real time or shear wave elastography, ANNA & Water diffusion and ADC \\
$\begin{array}{l}\text { Chemical } \\
\text { characteristics }\end{array}$ & Ultrasound resonance spectroscopy experimental & MR spectroscopy established, diagnostic value \\
Biopsy access & Lesions may be identified in real time & uncertain \\
& Much more flexibility in setting and anaesthetic requirements & Image fusion or cognitive targeting \\
Cost & $\$ 35,000-\$ 150,000$ & Approx $\$ 3$ million \\
\hline
\end{tabular}

ANNA, artificial neural network analysis; ADC, apparent diffusion coefficient.
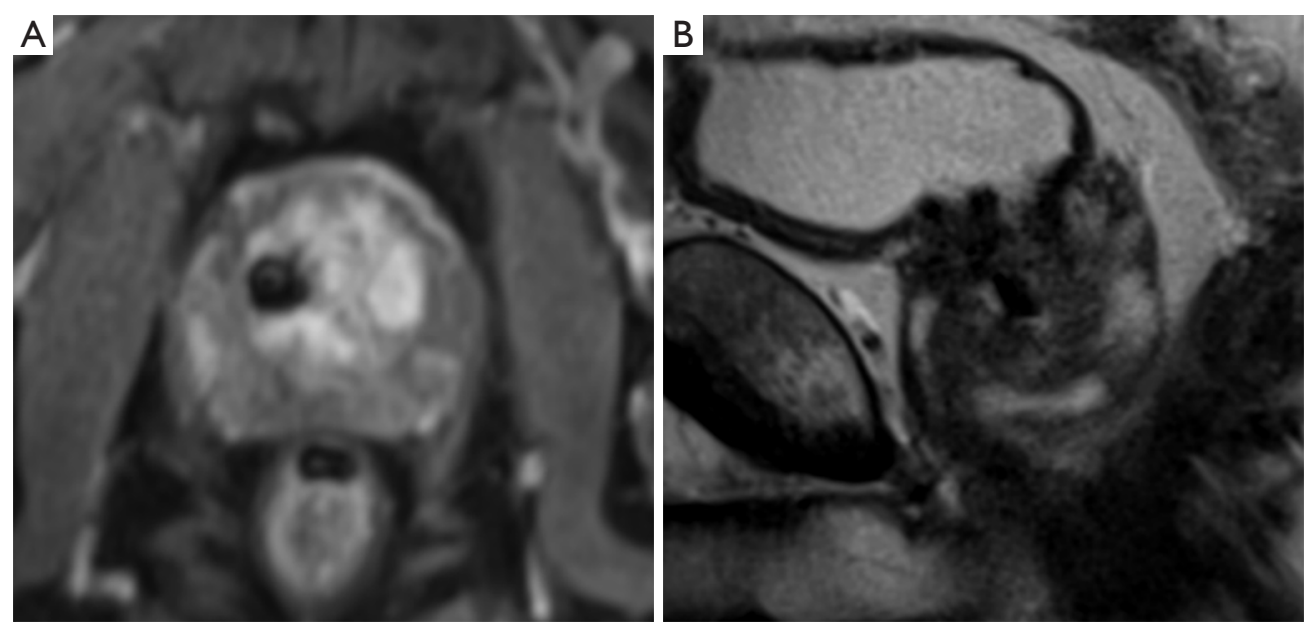

Figure 2 Axial DCE and sagittal multiparametric MRI images showing spherical (black) voids left by Urolift implants.

mpMRI takes 25 minutes and prostate mpUSS, currently conducted as part of a clinical trial 5-10 minutes (19). Contrast agent costs are similar, approximately $£ 40$ for each scan on the UK market. Table 1 compares some technical and logistic aspects of prostate ultrasound and mpMRI.

\section{Patient factors}

Diffusion weighted imaging (DWI) is vulnerable to image degradation from rectal gas and patient movement as well as the presence of metal prostheses.

Metal hip arthroplasty was performed in some 78,000 men yearly in the UK this decade, estimated to rise to
96,000 by the year $2035(20,21)$. It can impair T2 as well as DWI sequences of at least the ipsilateral prostate. Similarly the recent introduction of BPE treatments such as Urolift can be seen to produce spherical voids of $1 \mathrm{~cm}$ or so diameter for each implant used (Figure 2). This phenomenon requires standalone analysis but may need to be included in the consent process for these procedures, oft performed on a similar population of men as undergoes prostate cancer investigation.

Distant from the prostate, cardiac implants such as coronary artery stents or pacemakers, though increasingly compatible with MRI, may still impair investigations if recently placed or if records are unavailable. Claustrophobia 
Table 2 Recent reports on MRI or MRI targeted biopsy performance

\begin{tabular}{|c|c|c|c|c|}
\hline Lead author & Date & Type & Findings & $\mathrm{n}$ \\
\hline Hansen (8) & 2018 & Multicentre prospective series & $\begin{array}{l}\text { NPV } 80 \% \text {, PPV } 71 \% \text { (PIRADS } 4 \text { or 5), PPV } 31 \% \\
\text { (PI-RADS 3) (Gl } 7 \text { or higher significance threshold) }\end{array}$ & 807 \\
\hline Johnson (28) & 2019 & $\begin{array}{l}\text { Clinically significant prostate cancer } \\
\text { using prostatectomy histology as a } \\
\text { reference standard }\end{array}$ & $\begin{array}{l}\text { reporting a lower sensitivity of } 63 \% \text { though post biopsy } \\
\text { timing of a majority }(51 \%) \text { of mpMRI }\end{array}$ & 588 \\
\hline
\end{tabular}

Sens, sensitivity; Spec, specificity; NPV, negative predictive value; PPV, positive predictive value; mpMRI, multiparametric MRI.

is a common problem for patients undergoing MRI, affecting up to $15 \%$ of patients (22) and may prevent acquisition of MRI images altogether or add to movement artefact, degrading quality Finally renal impairment can preclude the administration of gadolinium contrast. Recent estimates for the UK prevalence of CKD 3-5 (eGFR of $59 \mathrm{~mL} / \mathrm{min} / 1.73 \mathrm{~m}^{2}$ ) between 1.8 and 3.6 million, approximately a third of whom will be men $(23,24)$.

Artefacts abound in ultrasound scanning also, prostate calcification in particular can obscure views, and signal attenuation occurs if the transducer-tissue interface is suboptimal, though unlike MRI the dynamic nature and live review of image acquisition allows for correction. Other weaknesses of ultrasound scanning resist efforts to overcome them, and in particular the greater distances involved in larger prostates. In the authors' experience the acquisition of high quality diagnostic ultrasound images, particularly of the anterior gland in prostates of $100 \mathrm{cc}$ or higher is challenging. Evidence on the tolerability of diagnostic transrectal ultrasound is limited but large series on scans where biopsies are taken also show high levels of tolerance (25).

\section{Detection of clinically significant prostate cancer}

mpMRI is a highly accurate test for the detection of clinically significant prostate cancer. Level one evidence from PROMIS revealed a sensitivity of $93 \%$ and negative predictive value of $89 \%$. Comparison of diagnostic performance between studies is hindered by significant heterogeneity in MRI parameters, definition of clinical significance chosen and biopsy route and protocol. Despite this a high sensitivity and negative predictive value are common findings across the summarised reports. Reports of inter reader variation in mpMRI lesion scoring however $(26,27)$ may impede its timely spread beyond expert centres. Even in such large centre lesser performance has been reported. Johnson and colleagues (28) analysed mpMRI performance in detecting clinically significant prostate cancer using prostatectomy histology as a reference standard and reported a lower sensitivity of $63 \%$, though the post biopsy timing of a majority $(51 \%)$ of their scans likely hindered interpretation.

The evidence base on the diagnostic performance of ultrasound in both PCa detection and localization continues to expand but could not yet be said to rival that of MRI. Our group conducted a review of ultrasound in the diagnosis of significant prostate cancer in 2016 (29) and concluded that whilst convincing evidence was yet to arise the newer ultrasound technologies showed promise, particularly if employed in combination with b-mode andDoppler USS in a manner analogous to mpMRI. Key reports to emerge since are summarised in Table 2, concentrating on shear wave elastography the modality of most recent attention, where tissue compression/relaxation is achieved by shear wave propagation using focused ultrasound beams, as well as artificial neural network analysis (ANNA).

Though encouraging figures are seen, study size and statistical weight are less and some elements of study design, for example the use of radical prostatectomy specimens as a reference standard which creates incorporation bias, can hinder interpretation. Many of the more promising studies into ultrasounds potential as a diagnostic imaging technique in prostate cancer employ techniques to smooth variation 

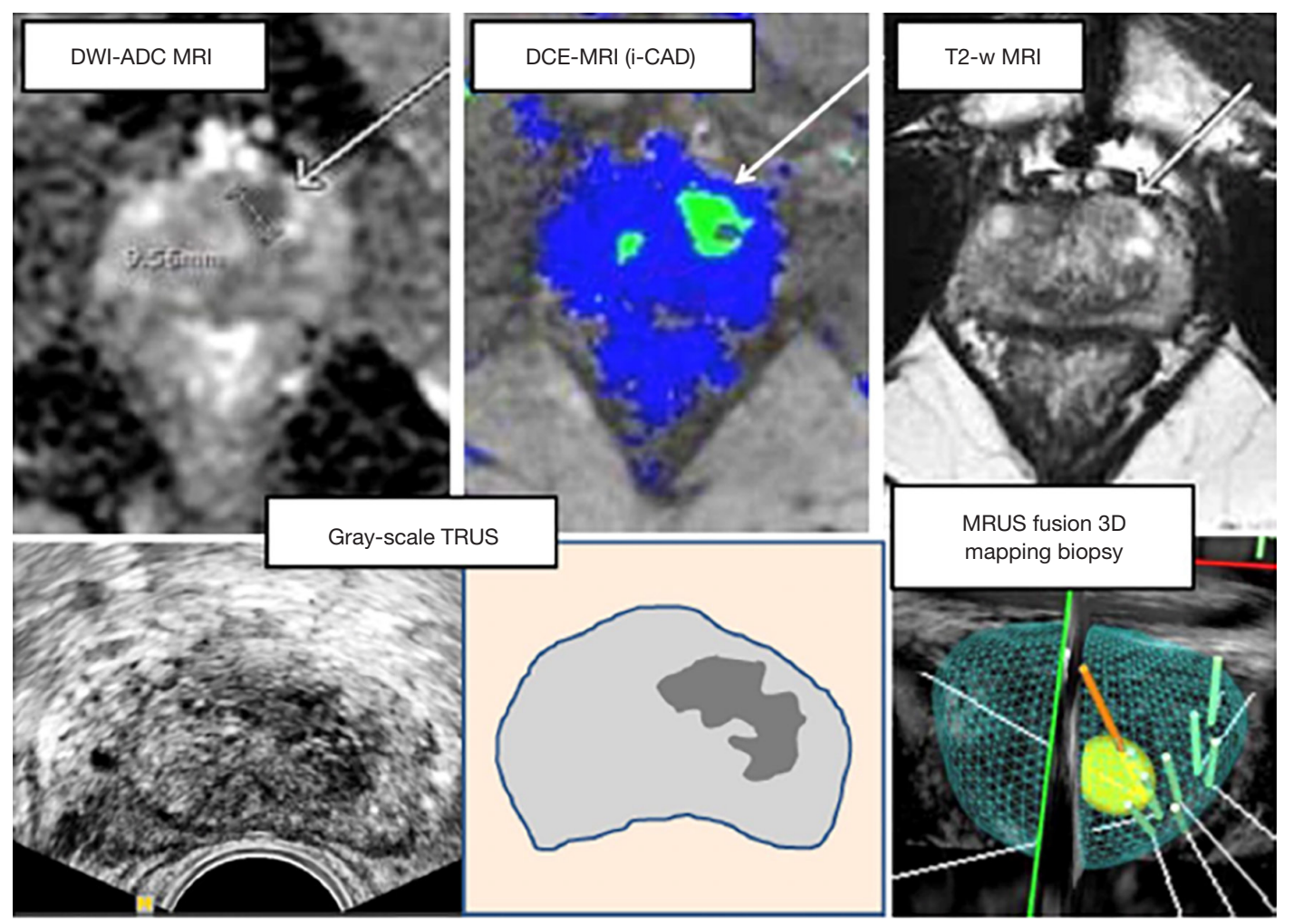

Figure 3 Ukimura et al. (34) demonstrate clearly visible TRUS lesions of patients with MRI positive findings in which the TRUS image information was utilized to direct biopsies. TRUS, transrectal ultrasound.

that arises from its operator dependent interpretation. Lee and colleagues in 2008 developed a scoring system from 1-5 to apply to b-mode and colour Doppler studies of 118 lesions and demonstrated a PPV of $80 \%$ and an AUC of 0.81 for a lesion score $4+(32)$.

Live TRUS images acquired in biopsy procedures have been analysed retrospectively and correlation found with lesions identified on pre-biopsy $\mathrm{mMRI}$ in $80 \%$ of cases (32). One of the earlier analyses (33) of targeted biopsy based on more than one ultrasound modality compared cancer detection in cores targeted on ultrasound appearance with those gathered by sextant sampling in a similar manner to PRECISION. Hypoechoic lesions as well as peripheral zone abnormalities on b-mode and those on Doppler ultrasound were sampled. Cancer was detected in $40 \%$ of patients with sonographically identified lesions versus $4 \%$ of those without. The use of ultrasound targeting overlooked $5 \%$ of diagnosed tumours versus $7 \%$ for sextant sampling. This strategy of opportunistic sampling of suspicious lesions seen on biopsy ultrasound scanning has widespread use for example in the recent MRI FIRST study, Loch et al. and
Tokas et al. 2004 and 2018 or as the German S3 guidelines (34-37). Figure 3 shows a prostate lesion appearing across USS and MRI scan type as well as a fusion view.

Algorithmic analysis of ultrasound imaging has long shown promise. A study of ANNA of transrectal ultrasound images (16) revealed cancer detection rates of $50 \%$ in a cohort of 132 men with prior negative zonal biopsy as well as the potential to reduce numbers of biopsy cores needed, a result borne out in long term follow up with a $50-75 \%$ reduction in core numbers and confirming no cancer or cancer in a curable stage in $97 \%$ at 12 years (35). The rapid development of machine learning technologies and applications recently create enormous potential for this approach (Figure 4). Table 3 summarises some key papers on the diagnostic performance of prostate ultrasound.

Evidence on the diagnostic performance of mpUSS in differing forms is pending from large clinical trials $(19,45)$ and it is hoped will deliver robust evidence on the question we consider in this article. Images from the CADMUS pilot are demonstrated in Figure 5. The potential benefit of mpUSS to complete with the demonstrated utility of mpMRI 

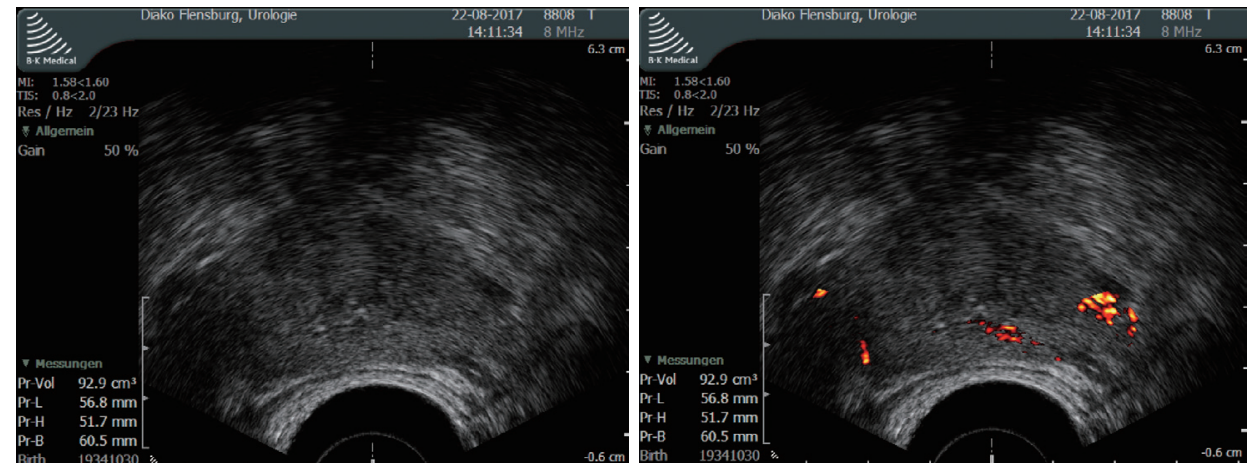

Figure 4 ANNA marks invisible cancer suspicious areas in red. Targeted biopsies revealed Gleason Score 3+4=7a prostate cancer.

Table 3 Recent reports on newer ultrasound technologies

\begin{tabular}{|c|c|c|c|c|c|}
\hline Lead author & Technology & Date & Type & Key findings & $\mathrm{N}$ \\
\hline Wildeboer (38) & $\begin{array}{l}\text { CEUS algorithmic } \\
\text { analysis }\end{array}$ & 2017 & Series, prostatectomy specimens & Sens $79 \%$, Spec $80 \%$, PPV $85 \%$, NPV $83 \%$ & 19 \\
\hline Porsch (40) & SWE & 2015 & Prospective series & $\begin{array}{l}\text { No significant difference between SWE } \\
\text { values for benign and malignant }\end{array}$ & 73 \\
\hline Correas (41) & SWE & 2015 & Prospective series & Sens $93 \%$, Spec 85\%, PPV 48\%, NPV 99\% & 184 men \\
\hline Drudi (42) & RTE & 2019 & Paired cohort & Sens $85 \%$, Spec $67 \%$ & 82 men \\
\hline Mannaerts (43) & mpUSS & 2019 & Prospective series & Sens $74 \%$ & 48 men \\
\hline Walz (44) & ANNA & 2013 & Prospective series & Sens $83 \%$, Spec $64 \%$ & 28 \\
\hline
\end{tabular}

Sens, sensitivity; Spec, specificity; NPV, negative predictive value; PPV, positive predictive value; CEUS, contrast-enhanced ultrasound; SWE, shear-wave elastography; ANNA, artificial neural network analysis.

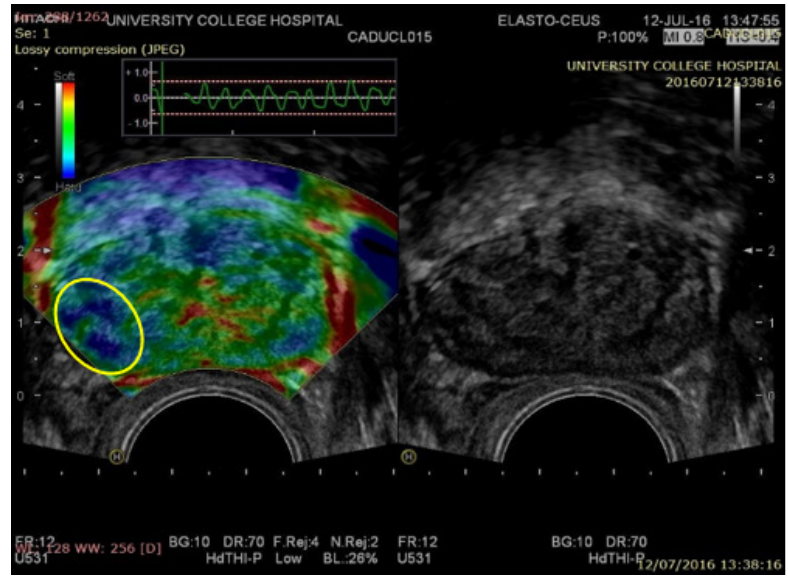

Decreased tissue elasticity in the right posteriolateral prostate which at biopsy revealed $3 \mathrm{~mm}$ GI 3+4

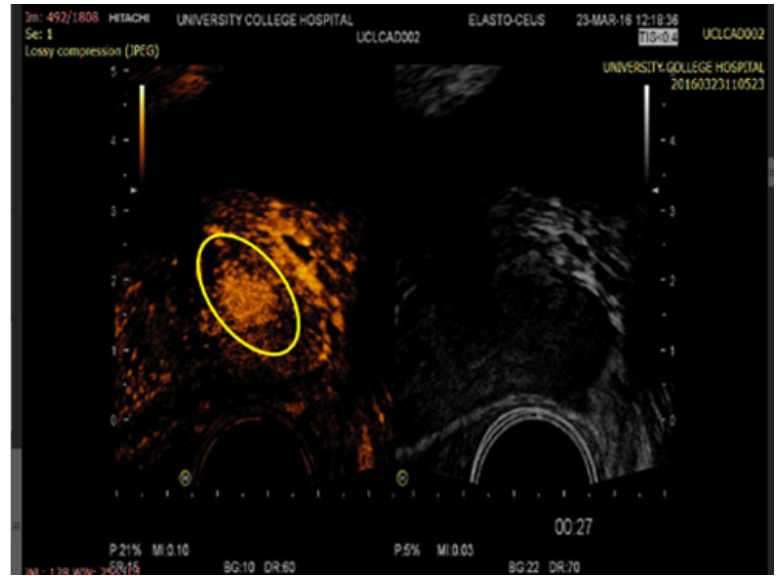

A large area of pronounced early contrast enhancement in the left anterior prostate. Biopsy revealed $15 \mathrm{~mm}$ of $\mathrm{Gl} 4+3$ adenocarcinoma.

Figure 5 mpUSS identification of prostate cancer. Images taken from CADMUS pilot (19). 
remains a contextual question of course. For many patients worldwide, presenting with a suspicion of prostate cancer and no access to MRI or modern forms of TRUS image targeted biopsies, the actual competition will be with random or sampling transrectal biopsy, a rather easier one to win.

\section{Conclusions}

Prostate ultrasound offers significant utilitarian advantage over mpMRI and has an emergent and expanding portfolio of encouraging diagnostic studies. It cannot, in evidential terms, claim parity on a level playing field with mpMRI but early results on mpUSS and ANNA are encouraging and the results of large clinical trials are awaited. The limitations of mpMRI in terms of cost, availability and contraindication mean that the playing field is not level, however.

For many men 12 core untargeted transrectal biopsy, a diagnostic test with comparable sensitivity to a coin toss, remains the standard and in this light, adding targeted biopsy using an imaging technology more accessible than MRI is very attractive. If its utility is convincingly demonstrated in the forthcoming trials ultrasound stands to compete with strength on a field where MRI is anyway often absent.

\section{Acknowledgments}

Funding: None.

\section{Footnote}

Provenance and Peer Review: This article was commissioned by the Guest Editors (Martin J. Connor, Saiful Miah, Taimur T. Shah, Hashim U. Ahmed) for the series "Prostate Imaging and Focal Therapy" published in Translational Andrology and Urology. The article was sent for external peer review organized by the Guest Editors and the editorial office.

Conflicts of Interest: All authors have completed the ICMJE uniform disclosure form (available at http://dx.doi. org/10.21037/tau.2020.02.26). The series "Prostate Imaging and Focal Therapy" was commissioned by the editorial office without any funding or sponsorship. MJC served as the unpaid Guest Editor of the series. ADR Grey has received salary payments from Prostate Cancer UK and the Moulton foundation grant, for his work on the CADMUS trial (ISRCTN38541912) investigating the role of multiparametric ultrasound in clinically significant prostate cancer detection. Hitachi and BK ultrasound provided hardware and software upgrades at reduced cost to facilitate this trial. MJ Connor conducts prostate cancer research funded by the Welcome Trust and University College London Hospital charity. T Loch is inventor of the ANNA/ C-TRUS method and shareholder of ANNA Technologies/ Deutschland, has received consultation fees from ANNA Technologies and has received teaching equipment from BK Medical. Dr. Tam has no other conflicts of interest to declare.

Ethical Statement: The authors are accountable for all aspects of the work in ensuring that questions related to the accuracy or integrity of any part of the work are appropriately investigated and resolved.

Open Access Statement: This is an Open Access article distributed in accordance with the Creative Commons Attribution-NonCommercial-NoDerivs 4.0 International License (CC BY-NC-ND 4.0), which permits the noncommercial replication and distribution of the article with the strict proviso that no changes or edits are made and the original work is properly cited (including links to both the formal publication through the relevant DOI and the license). See: https://creativecommons.org/licenses/by-nc-nd/4.0/.

\section{References}

1. Ahmed HU, El-Shater Bosaily A, Brown LC, et al. Diagnostic accuracy of multi-parametric MRI and TRUS biopsy in prostate cancer (PROMIS): a paired validating confirmatory study. Lancet 2017;389:815-22.

2. Kasivisvanathan V, Rannikko AS, Borghi M, et al. MRI targeted or standard biopsy for prostate cancer diagnosis. N Engl J Med 2018;378:1767-77.

3. Loeb S, van den Heuvel S, Zhu X, et al. Infectious complications and hospital admissions after prostate biopsy in a European randomized trial. Eur Urol 2012;61:1110-4.

4. Seitz M, Stief C, Waidelich R, et al. Transrectal ultrasound guided prostate biopsy in the era of increasing fluoroquinolone resistance: prophylaxis with single-dose ertapenem. World J Urol 2017;35:1681-8.

5. Naber KG, Wagenlehner FME. Novel Antibiotics in the Treatment of Urinary Tract Infections. Eur Urol Focus 2019;5:10-2.

6. Miah S, Eldred-Evans D, Simmons LAM, et al. Patient Reported Outcome Measures for Transperineal Template Prostate Mapping Biopsies in the PICTURE Study. J Urol 
2018;200:1235-40.

7. Grey A, Hartington T, Allen C, et al. Transperineal MRI visually-targeted prostate biopsies compared to template mapping biopsy in 534 men requiring further risk stratification. J Urol 2016;195:e697-8.

8. Hansen NL, Barrett T, Kesch C, et al. Multicentre evaluation of magnetic resonance imaging supported transperineal prostate biopsy in biopsy naïve men with suspicion of prostate cancer. BJU Int 2018;122:40-9.

9. Mottet N, van den Burgh RCN, Briers Eet al. EAU guidelines on prostate cancer. Updated 2019. Available online: https://uroweb.org/guideline/prostate-cancer/

10. Fulgham PF, Rukstalis DB, Turkbey IB, et al. AUA Policy Statement on the Use of Multiparametric Magnetic Resonance Imaging in the Diagnosis, Staging and Management of Prostate Cancer. J Urol 2017;198:832-8. PubMed http://dx.doi.org/10.1016/j.juro.2017.04.101

11. Mahal BA, Berman RA, Taplin ME, et al. Prostate CancerSpecific Mortality Across Gleason Scores in Black vs Nonblack Men. JAMA 2018;320:2479-81.

12. Mansfield P, Maudsley AA. Medical Imaging by NMR. Br J Radiol 1977;50:188-94.

13. Dussik KT. The ultrasonic field as a medical tool. Am J Phys Med 1954;33:5-20. PubMed

14. Holm HH, Gammelgaard J. Ultrasonically guided precise needle placement in the prostate and the seminal vesicles. J Urol 1981;125:385-7.

15. Halpern EJ, Strup SE. Using gray-scale and color and power Doppler sonography to detect prostatic cancer. AJR Am J Roentgenol 2000;174:623-7.

16. Loch T. Computerized transrectal ultrasound (C-TRUS) of the prostate: detection of cancer in patients with multiple negative systematic random biopsies. World J Urol 2007;25:375-80.

17. Ahmed HU, Kirkham A, Arya M, et al. Is it time to consider a role for MRI before prostate biopsy? Nat Rev Clin Oncol 2009;6:197-206.

18. Ogbole GI, Adeyomoye AO, Badu-Peprah A, et al. Survey of magnetic resonance imaging availability in West Africa. Pan Afr Med J 2018;30:240.

19. Grey A, Scott R, Charman S, et al. The CADMUS trial Multi-parametric ultrasound targeted biopsies compared to multi-parametric MRI targeted biopsies in the diagnosis of clinically significant prostate cancer. Contemp Clin Trials 2018;66:86-92.

20. National Joint Registry for England and Wales: 9th Annual Report 2012.

21. Culliford D, Maskell J, Judge A, et al. Future projections of total hip and knee arthroplasty in the UK: results from the UK Clinical Practice Research Datalink. Osteoarthritis Cartilage 2015;23:594-600.

22. Murphy KJ, Brunberg JA. Adult claustrophobia, anxiety and sedation in MRI. Magn Reson Imaging 1997;15:51-4.

23. The Information Centre for health and social care. Prevalence Data Tables. Leeds: The NHS Information Centre for health and social care, 2011. Available online: http://www.ic.nhs.uk/statistics-and-data-collections/ supporting-information/audits-and-performance/thequalityand-outcomes-framework/qof-2009-10/data-tables/ prevalence-data-tables

24. Stevens PE, O'Donoghue DJ, de Lusignan S, et al. Chronic kidney disease management in the United Kingdom: NEOERICA project results. Kidney Int 2007;72:92-9.

25. Vázquez Rodríguez A, Quirce AF. Safety and tolerance of transrectal ultrasound-guided (TRUS) biopsy in the diagnosis of prostate cancer. Radiologia 2007;49:417-23.

26. Müller S, Lilleaasen G, Sand TE, et al. Poor reproducibility of PIRADS score in two multiparametric MRIs before biopsy in men with elevated PSA. World J Urol 2018;36:687-91.

27. Sonn GA, Fan R, Ghanouni P, et al. Prostate Magnetic Resonance Imaging Interpretation Varies Substantially Across Radiologists. Eur Urol Focus 2019;5:592-9.

28. Johnson DC, Raman SS, Mirak SA, et al. Detection of Individual Prostate Cancer Foci via Multiparametric Magnetic Resonance Imaging. Eur Urol 2019;75:712-20.

29. Grey A, Ahmed HU. Multiparametric ultrasound in the diagnosis of prostate cancer. Curr Opin Urol 2016;26:114-9.

30. Fütterer JJ, Briganti A, De Visschere PD, et al. Can Clinically Significant Prostate Cancer Be Detected with Multiparametric Magnetic Resonance Imaging? A Systematic Review of the Literature. Eur Urol 2015;68:1045-53.

31. Siddiqui MM, Soroush RB, Baris T, et al. Comparison of MR/Ultrasound fusion-guided biopsy with ultrasound guided biopsy for the diagnosis of prostate cancer. JAMA 2015;313:390-7.

32. Lee HY, Lee HJ, Byun S, et al. Classification of Focal Prostatic Lesions on Transrectal Ultrasound (TRUS) and the Accuracy of TRUS to Diagnose Prostate Cancer. Korean J Radiol 2009;10:244-51.

33. Loch T, Eppelmann U, Lehmann J, et al. Transrectal ultrasound guided biopsy of the prostate: random sextant versus biopsies of sono-morphologically suspicious lesions. World J Urol 2004;22:357-60. 
34. Ukimura O, Marien A, Palmer S, et al. Trans-rectal ultrasound visibility of prostate lesions identified by magnetic resonance imaging increases accuracy of imagefusion targeted biopsies. World J Urol 2015;33:1669-76.

35. Tokas T, Grabski B, Paul U, et al. A 12-year followup of ANNA/C-TRUS image-targeted biopsies in patients suspicious for prostate cancer. World J Urol 2018;36:699-704.

36. Rouvière $\mathrm{O}$, Puech $\mathrm{P}$, Renard-Penna R. Use of prostate systematic and targeted biopsy on the basis of multiparametric MRI in biopsy-naive patients (MRIFIRST): a prospective, multicentre, paired diagnostic study. Lancet Oncol 2019;20:100-9.

37. Interdisziplinäre Leitlinie der Qualität S3 zur Früherkennung, Diagnose und Therapie der verschiedenen Stadien des Prostatakarzinoms, Langversion 5.1, 2019, AWMF Registernummer: 043/022OL, Available online: http://www.leitlinienprogramm-onkolo-gie.de/leitlinien/ prostatakarzinom/

38. Wildeboer RR, Postema AW, Demi L, et al. Multiparametric dynamic contrast-enhanced ultrasound imaging of prostate cancer. Eur Radiol 2017;27:3226-34.

39. Wei C, Li C, Szewczyk-Bieda M, et al. Performance

Cite this article as: Grey ADR, Connor MJ, Tam J, Loch T. Can transrectal prostate ultrasound compete with multiparametric MRI in the detection of clinically significant prostate cancer? Transl Androl Urol 2020;9(3):1492-1500. doi:10.21037/tau.2020.02.26
Characteristics of Transrectal Shear Wave Elastography Imaging in the Evaluation of Clinically Localized Prostate Cancer: A Prospective Study. J Urol 2018;200:549-58.

40. Porsch M, Wendler JJ, Liehr UB, et al. New aspects in shear-wave elastography of prostate cancer. J Ultrason 2015;15:5-14.

41. Correas JM, Tissier AM, Khairoune A, et al. Prostate cancer: Diagnostic performance of real-time shearwave elastography. Radiology 2015;275:280-9.

42. Drudi FM, Cantisani V, Angelini F, et al. Multiparametric MRI versus Multiparametric US in the detection of prostate cancer. Anticancer Res 2019;39:3101-10.

43. Mannaerts CK, Wildeboer RR, Remmers S, et al. Multiparametric ultrasound for prostate cancer detection and localization: Correlation of b-mode, shearwave elastography and contrast enhanced ultrasound with radical prostatectomy specimens. J Urol 2019;202:1166-73.

44. Walz J, Loch T, Salomon G et al Imaging of the prostate. Urologe A 2013;52:490-6.

45. PROSTOGRAM (Prostate cancer screening trial using imaging) ISRCTN43502108. Available online: https:// clinicaltrials.gov/ct2/show/NTC03702439 